\title{
USE OF THE ORAC-PYROGALLOL RED/ORAC-FLUORESCEIN RATIO TO ASSESS THE QUALITY OF ANTIOXIDANTS IN CHILEAN WINES
}

\author{
C. LÓPEZ-ALARCÓN, ${ }^{1 *}$ R. ORTÍZ, ${ }^{1} J$. BENAVIDES, ${ }^{l}$ E. MURA, ${ }^{l}$ E. LISSI $^{2}$ \\ ${ }^{1}$ Departamento de Farmacia, Facultad de Química, Pontificia Universidad Católica de Chile. C.P. 782 0436, Santiago, Chile. \\ 2 Facultad de Quimica y Biología, Universidad de Santiago de Chile, USACH.
}

(Received: November 11, 2010 - Accepted: May 10, 2011)

\begin{abstract}
We have recently proposed that ORAC ( $\underline{\text { Oxygen }} \underline{\text { Radical }}$ Absorbance Capacity) methods employing fluorescein (ORAC-FL) and pyrogallol red (ORACPGR) as target molecules could be considered as complementary indexes. In particular, the ratio ORAC-PGR/ORAC-FL would reflect the average quality of the antioxidants present in a particular sample. In the present work, we evaluated the antioxidant capacity and the total phenol content of twelve Chilean wines (red, rose, and white) employing ORAC and Folin-Ciocalteau methods, respectively. Red wines showed higher Folin and ORAC values than rose and white wines. However, the ORAC-PGR/ORAC-FL ratio of all tested wines was close to 0.5 . The results show that it is important to consider both, the phenol content of the sample (measured by ORAC-FL or Folin indexes) and their average reactivity (measured by the ORAC-PGR/ORAC-FL ratio). Both factors are considered relevant in the evaluation of the antioxidant capacity of wines.
\end{abstract}

Key Words: Antioxidant capacity; ORAC; wines; pyrogallol red; fluorescein

\section{INTRODUCTION}

It is recognized that a moderate consumption of beverages with high content of polyphenols, such as wines, reduces the incidence of coronary heart diseases (CHD), atherosclerosis and platelet aggregation. ${ }^{1-3}$ These associations have been, at least partially, explained by the ability of polyphenols to react with reactive oxygen species (ROS) ${ }^{4-6}$ These evidences have lead to evaluate the in vitro antioxidant capacity of wines using methodologies that involve different concepts and experimental conditions. ${ }^{7-10}$ Among the employed assays, ORAC (Oxygen Radical Absorbance Capacity) is one of the most used methods. This assay evaluates the capacity of antioxidants (or their complex mixtures) to inhibit the bleaching of a target molecule (probe) induced by peroxyl radicals. ORAC assay originally used phycoerythrin as probe. ${ }^{11}$ However, at present, fluorescein (FL) is the target molecule of choice (ORAC-FL) ${ }^{12,13}$ Usually, Trolox and 2,2'-Azo-bis(2-amidinopropane) dihydrochloride (AAPH) are employed as reference antioxidant and peroxyl radical source, respectively. ${ }^{14}$

The consumption of FL is commonly inhibited, even by antioxidants of low reactivity, throughout kinetic profiles characterized by the presence of induction times. ${ }^{15,16}$ Therefore, ORAC-FL values would be more influenced by the stoichiometry of the reaction (defined as the number of radicals that each additive molecule can remove) than by the reactivity of the additives. Based on these observations, we have proposed the use of pyrogallol red (PGR) as probe in an ORAC-like methodology (ORAC-PGR). The consumption of PGR is inhibited by reactive antioxidants without generating induction times. ${ }^{15,17}$ In particular, among all tested antioxidants, only ascorbic acid protected PGR through a clear induction time. ${ }^{18,19}$ The absence of induction times in the protective kinetic profiles of PGR would imply that the ORAC-PGR index is more related to the reactivity of the antioxidants than to stoichimetric factors. Taking into account the characteristics of ORAC-FL and ORAC-PGR assays, we have recently proposed that both methods could be considered as rendering complementary indexes. ${ }^{20}$ Thus, the ORAC-PGR/ORAC-FL ratio would reflect the quality of the antioxidants present in a particular sample. ${ }^{20}$ We have reported that the ORAC-PGR/ORAC-FL ratio of green tea is almost 7.5 times higher than that of Haploppapus baylahuen, implying that green tea contains antioxidants of better quality than the compounds contained in the Hapoplappus baylahuen infusion. ${ }^{20} \mathrm{~A}$ similar approach has been used by Niki and co-workers, using PGR and Pyranine as target molecules to estimate the antioxidant capacity of beverages and foods..$^{21-23}$

In the present work, we evaluated the antioxidant capacity and the total phenol content of twelve Chilean wines (red, rose, and white wines) employing ORAC and Folin-Ciocalteau methods. In particular, the experiments were focused to estimate the antioxidant quality of the samples by the ORAC-PGR/
ORAC-FL ratio. Red wines showed higher ORAC values than rose and white wines. However, all tested wines gave similar ORAC-PGR/ORAC-FL ratios.

\section{EXPERIMENTAL}

\subsection{Chemicals}

2,2'-Azo-bis(2-amidinopropane) dihydrochloride (AAPH), was used as peroxyl radical source. Pyrogallol red (PGR), Trolox (6-hydroxy-2,5,8tetramethylchroman-2-carboxylic acid), fluorescein disodium salt (FL), and AAPH, were purchased from Sigma-Aldrich (St. Louis, MO). Folin-Ciocalteau reactive and sodium carbonate were supplied by Merck (Darmstadt, Germany). Wine samples were obtained from local markets. The year of the harvest and denomination of origin (d.o.) were:

\section{Red wines:}

Cabernet Sauvignon-1: 2006, d.o. valle de Casablanca.

Cabernet Sauvignon-2: 2005, d.o. valle Central.

Cabernet Sauvignon-3: 2005, d.o. valle Central.

Carmenere: 2004, d.o. valle Central.

Merlot: 2006, d.o. valle Central.

Syrah: 2005, d.o. valle del Limarí.

Rose wines:

Rose-1: 2006, d.o. valle de Colchagua.

Rose-2: 2007, d.o. valle Central.

White wines:

Chardonnay-1: 2004, d.o. valle de Casablanca.

Chardonnay-2: 2004, d.o. valle de Casablanca.

Chardonnay-3: 2003, d.o. valle de Casablanca.

Late harvest: 2006, d.o. valle de Colchagua.

\subsection{Total phenolics}

Total phenol content of wines was determined according to the FolinCiocalteau colorimetric method, ${ }^{24}$ using Trolox as standard. Appropriate dilutions of the samples $(1 \mathrm{~mL})$ were added to $0.2 \mathrm{~N}$ Folin-Ciocalteau reagent $(5 \mathrm{~mL})$. After $5 \mathrm{~min}$ incubation, $4 \mathrm{~mL}$ of sodium carbonate $(75 \mathrm{~g} / \mathrm{L})$ were added. The solutions were incubated for 2 hours at room temperature and the absorbance intensity (at $740 \mathrm{~nm}$ ) was measured using a Hewlett Packard 8453 spectrophotometer. Quantification was carried out on the basis of the standard curve of Trolox, and the results were expressed as Trolox equivalents (mM).

\subsection{ORAC determinations}

ORAC values of wines were estimated according to previous works. ${ }^{15,17,19}$ Briefly, a solution containing PGR $(5 \mu \mathrm{M})$ or FL $(70 \mathrm{nM})$, AAPH $(10 \mathrm{mM})$ 
with or without the wine sample was incubated at $37^{\circ} \mathrm{C}$ in phosphate buffer 75 $\mathrm{mM}, \mathrm{pH}$ 7.4. PGR consumption was evaluated from its absorption intensity (A) decrease at $540 \mathrm{~nm}$, while FL consumption was evaluated from its decrease in the fluorescence intensity ( $\mathrm{F}$, excitation: $493 \mathrm{~nm}$; emission: 515 $\mathrm{nm}$ ). UV-visible experiments were carried out in a Hewlett Packard 8453 (Palo Alto, CA, USA) or an Unicam Helios-a (Cambridge, England) UV-visible spectrophotometer. The fluorescence of FL was evaluated employing a Perkin Elmer LS-55 spectrofluorimeter (Beaconsfield, U.K). Control solutions (in the absence of wines, $\mathrm{A}_{0}$ or $\mathrm{F}_{0}$ ) showed a fast consumption of the probes (before 20 minutes). Values of $\left(\mathrm{A} / \mathrm{A}_{0}\right)$ or $\left(\mathrm{F} / \mathrm{F}_{0}\right)$ were plotted as a function of time. Integration of the area under the curve (AUC) was performed up to a time such that $\left(\mathrm{F} / \mathrm{F}_{0}\right)$ or $\left(\mathrm{A} / \mathrm{A}_{0}\right)$ reached a value of 0.2 . These areas were employed to obtain ORAC values, according to Equation [1]. All experiments were carried out in triplicate.

$$
O R A C=\frac{\left(A U C-A U C^{0}\right)}{\left(A U C_{\text {Trobs }}-A U C^{0}\right)} f[\text { Trolox }]
$$

Where:

AUC $=$ Area under curve in the presence of the tested wine sample, integrated between time zero and that corresponding to $80 \%$ of the probe consumption;

$\mathrm{AUC}^{\circ}=$ Area under curve of control (PGR or FL plus AAPH solution)

$\mathrm{AUC}_{\text {Trolox }}=$ Area under curve in the presence of Trolox.

$\mathrm{f}=$ Dilution factor, equal to the ratio between the total volume of the working solution (target molecule plus AAPH, plus wine sample) and the added wine sample volume.

$[$ Trolox $]=$ Trolox milimolar concentration .

\section{RESULTS AND DISCUSSION}

Recently we have proposed that the ratio between ORAC-PGR and ORAC-FL could be considered as a useful index to estimate the quality of the antioxidants contained in a complex mixture. ${ }^{20} \mathrm{~A}$ high value of the ratio would imply that a high proportion of the antioxidants contained in a particular sample are able to efficiently protect PGR. From this assumption, we have estimated the antioxidant capacity of different complex mixtures such as tea and herbal infusions..$^{20}$ The ORAC-PGR/ORAC-FL ratio of tea infusions was near 5 times higher than that of herbal infusions. ${ }^{20}$ These results were ascribed to differences in the quality of the antioxidants present in tea and herbal infusions. Interestingly, the difference of the ORAC ratio was similar to the observed difference in ORAC-PGR values. In fact, ORAC-PGR values of tea infusions were 7.4 times higher than those of herbal infusions.

\subsection{Phenol content and antioxidant capacity of Chilean wines}

We estimated, employing ORAC-PGR and ORAC-FL methods (and also their ratio), the antioxidant capacity of Chilean wines. In addition, the total phenol content of the samples was estimated by the Folin Ciocalteau assay. As shown in Table 1, the mean of the Folin values of red, rose, and white wines was $4.5,0.9$, and $0,6 \mathrm{mM}$ Trolox equivalents, respectively. These results imply that the concentration of polyphenols in red wines was 5 , and 7.5 times higher than that of rose and white wines, respectively. These data are in agreement with previous reports that have shown a higher phenol content in red wines than in rose and white wines. ${ }^{25-27}$

ORAC-FL values of the tested wines were estimated from the area under the curve of kinetic profiles associated to the inhibition by wines of the consumption of FL induced by peroxyl radicals. Typical results are shown in Figure 1. As was expected, the kinetic profiles were characterized by the presence of neat induction times. As it is shown in Table 1, the mean of ORACFL values changed from 46 to 5.0 for red and white wines, respectively. These values appear to be close to 10 times higher than Folin values, a difference that could be explained by different stoichiometry of the reaction of polyphenols with Folin reagent and their reaction with AAPH derived peroxyl radicals. Interestingly, as obtained for the total phenol content, red wines showed ORACFL values 5.1 and 9.2 times higher than rose and white wines, respectively.

All tested wines inhibited the consumption of PGR mediated by peroxyl radicals. As shown in Figure 2 (where is presented a typical kinetic profile), the protective effect on PGR consumption given by wines was evidenced by kinetic profiles characterized by the absence of induction times. Table 1 shows the ORAC-PGR values of the wines. These data show that all ORACPGR values are lower than ORAC-FL. This result could be explained if it is considered that only a fraction of the phenols contained in wines was able to protect PGR. ORAC-PGR values of red wines were 5.2 and 7.9 higher than those of rose and white wines, respectively. These relations are very similar to those obtained from ORAC-FL data.

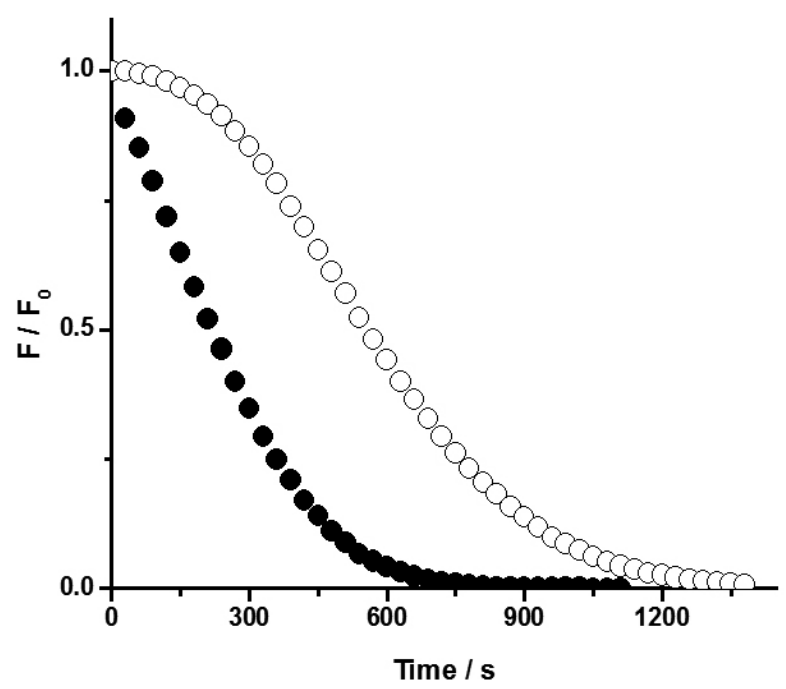

Figure 1: Kinetic profiles of FL consumption mediated by AAPH derived peroxyl radicals in the absence $(\square)$ and presence of a red wine $(\square)$. FL $(70 \mathrm{nM})$ was incubated in presence of AAPH $(10 \mathrm{mM})$ and a Syrah wine $(0.03 \mu \mathrm{L} / \mathrm{mL})$ in phosphate buffer $(75 \mathrm{mM}, \mathrm{pH} 7.4)$ at $37^{\circ} \mathrm{C}$.

Table 1

\begin{tabular}{|l|c|c|c|c|}
\hline & Folin & $\begin{array}{c}\text { ORAC- } \\
\text { FL }^{\mathrm{a}, \mathrm{b}}\end{array}$ & $\begin{array}{c}\text { ORAC- } \\
\text { PGR }^{\mathrm{a}, \mathrm{b}}\end{array}$ & $\begin{array}{c}\text { ORAC- } \\
\text { PGR/ } \\
\text { ORAC-FL }\end{array}$ \\
\hline Red wines & & & & \\
\hline Cabernet Sauvignon-1 & $4.7 \pm 0.1$ & $44 \pm 3$ & $31 \pm 3$ & 0.7 \\
\hline Cabernet Sauvignon-2 & $4.6 \pm 0.1$ & $56 \pm 1$ & $25 \pm 1$ & 0.5 \\
\hline Cabernet Sauvignon-3 & $5.9 \pm 0.2$ & $45 \pm 7$ & $19 \pm 1$ & 0.4 \\
\hline Carmenere & $4.2 \pm 0.1$ & $49 \pm 9$ & $25 \pm 2$ & 0.5 \\
\hline Merlot & $3.6 \pm 0.1$ & $38 \pm 4$ & $18 \pm 1$ & 0.5 \\
\hline Syrah & $4.1 \pm 0.2$ & $44 \pm 8$ & $20 \pm 2$ & 0.5 \\
\hline Mean & $4.5 \pm 0.1$ & $46 \pm 6$ & $23 \pm 2$ & 0.5 \\
\hline Rose wines & & & & \\
\hline Rose-1 & $0.8 \pm 0.1$ & $9.5 \pm 1.3$ & $4.0 \pm 0.1$ & 0.4 \\
\hline Rose-2 & $0.9 \pm 0.2$ & $8.5 \pm 0.7$ & $4.7 \pm 0.3$ & 0.6 \\
\hline Mean & $0.9 \pm 0.2$ & $9.0 \pm 1.0$ & $4.4 \pm 0.3$ & 0.5 \\
\hline White wines & & & & \\
\hline Chardonnay-1 & $0.6 \pm 0.2$ & $5.0 \pm 0.5$ & $3.3 \pm 0.2$ & 0.7 \\
\hline Chardonnay-2 & $0.5 \pm 0.1$ & $4.5 \pm 0.4$ & $2.3 \pm 0.1$ & 0.5 \\
\hline Chardonnay-3 & $0.6 \pm 0.2$ & $6.1 \pm 0.3$ & $2.7 \pm 0.1$ & 0.4 \\
\hline Late harvest & $0.6 \pm 0.1$ & $4.4 \pm 0.5$ & $3.3 \pm 0.4$ & 0.8 \\
\hline Mean & $0.6 \pm 0.2$ & $5.0 \pm 0.5$ & $2.9 \pm 0.3$ & 0.6 \\
\hline
\end{tabular}

Total phenolic content, ORAC-pyrogallol red (ORAC-PGR), ORACfluorescein (ORAC-FL) values and ORAC-PGR/ORAC-Fl ratio of chilean wines.

${ }^{a}$ Values are expressed as $\mathrm{mM}$ Trolox equivalents.

b Evaluated as described in experimental section. Values $(n=3)$ represent the concentration $(\mathrm{mM})$ of a Trolox solution that produces the same effect that the tested wine. 


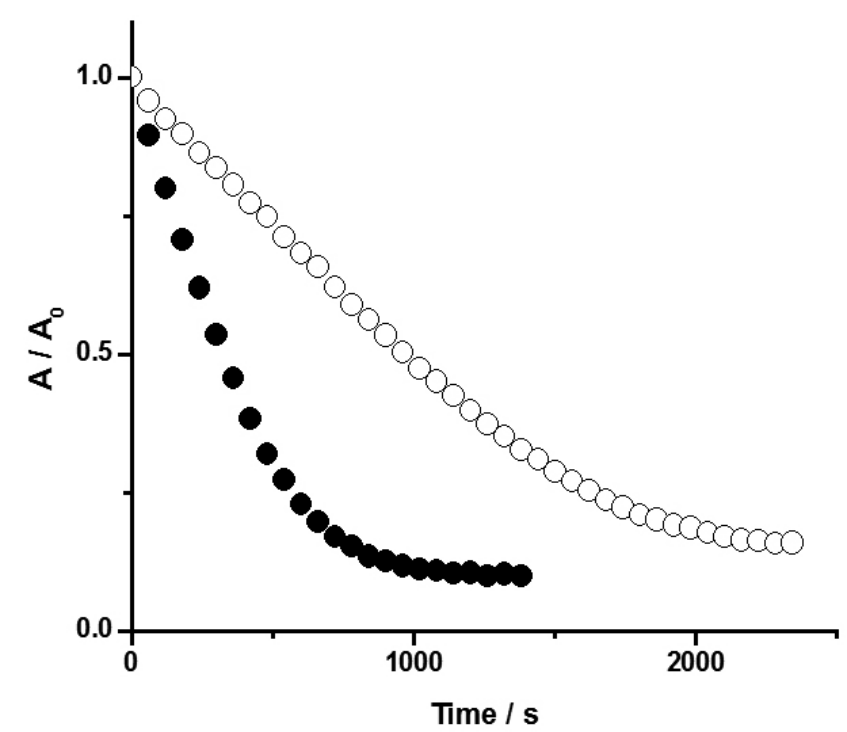

Figure 2: Kinetic profiles of PGR consumption mediated by AAPH derived peroxyl radicals in the absence $(\square)$ and presence of a red wine ( $\square$ ). PGR $(5 \mu \mathrm{M})$ was incubated in presence of AAPH $(10 \mathrm{mM})$ and a red cabernet sauvignon wine $(0.5 \mu \mathrm{L} / \mathrm{mL})$ in phosphate buffer $(75 \mathrm{mM}, \mathrm{pH} 7.4)$ at $37^{\circ} \mathrm{C}$.

Table 2

\begin{tabular}{|l|c|}
\hline & ORAC-PGR/ORAC-FL \\
\hline Tea infusions ${ }^{\mathrm{a}}$ & 0.10 \\
\hline Black tea-1 & 0.14 \\
\hline Black tea-2 & 0.15 \\
\hline Green tea & 0.17 \\
\hline White tea & 0.14 \\
\hline Mean & \\
\hline Herbal infusions & $0.008^{\mathrm{a}}$ \\
\hline Chenopodium ambrosioides & $0.011^{\mathrm{a}}$ \\
\hline Buddleia globosa & $0.012^{\mathrm{b}}$ \\
\hline Erythroxylum coca & $0.021^{\mathrm{b}}(0.011 \mathrm{a})$ \\
\hline Aloysia citriodora & $0.021^{\mathrm{a}}$ \\
\hline Matricaria chamomilla & $0.019^{\mathrm{a}}$ \\
\hline Peumus boldus & $0.020^{\mathrm{a}}$ \\
\hline Haplopappus baylahuen & $0.025^{\mathrm{b}}$ \\
\hline Mentha piperita & $0.045^{\mathrm{b}}$ \\
\hline Plantago major & $0.055^{\mathrm{b}}$ \\
\hline Tilia spp & $0.10^{\mathrm{b}}$ \\
\hline Rosa moschata & 0.029 \\
\hline Mean & \\
\hline Berry extracts & \\
\hline Blueberry & 0.24 \\
\hline Blackberry & 0.38 \\
\hline Raspberry & 0.50 \\
\hline Mean & 0.37 \\
\hline
\end{tabular}

ORAC-PGR/ORAC-FL ratio of berry extracts, teas and herbal infusions. Data taken from: ${ }^{\mathrm{a}} \mathrm{ref} .17{ }^{\mathrm{b}} \mathrm{ref} .20{ }^{\mathrm{c}}{ }^{\mathrm{r}}$ ref. 19

3.2 Use of the ORAC-PGR/ORAC-FL ratio to assess antioxidant quality of Chilean wines.

The data presented in Figures $\mathbf{1}$ and $\mathbf{2}$, and Table $\mathbf{1}$ show that, as expected, the use of different target molecules generated different kinetic profiles associated to the inhibition of their consumption by wines. From the area under the curve of the kinetic profiles, different ORAC values were obtained when FL and PGR were used as probes. Systematically ORAC-PGR values were close to one half ORAC-FL values, leading to similar ORAC-PGR/ORAC-FL ratios. In fact, ORAC-PGR/ORAC-FL ratios (mean) for red, rose, and white wines of $0.5,0.5$, and 0.6 , were estimated, respectively. These results would imply that all tested wines contain antioxidants of similar quality, and are in agreement to the antioxidant capacity of wines estimated by TRAP (Total Radical Antioxidant Potential) and TAR (Total Antioxidant Reactivity) methodologies. ${ }^{28,7}$ TRAP assay computes stoichiometric factors, while the TAR index is related to the reactivity of the antioxidants towards peroxyl radicals. ${ }^{28,7}$ In fact, the TAR/ TRAP ratio (proposed as a measured of the antioxidant quality) of red and white wines were 0.5 and 0.6 , respectively. ${ }^{7}$ The similarity in TAR/TRAP and ORAC-PGR/ORAC-FL values support the proposal that both ratios evaluate the mean reactivity of the antioxidants present in the samples.

In comparison with others rich polyphenolic samples, the ORAC-PGR/ ORAC-FL ratio of wines was 3.8 and 18.3 times higher than the mean value of tea and herbal infusions, respectively (Table 2). ${ }^{20}$ In addition, ORAC-PGR/ ORAC-FL ratio of wines was similar to that of raspberry extracts, but was 2.0 times higher than that of blueberry fruits extract (Table 2).${ }^{19}$ This could indicate that, in average, the reactivity of the phenols present in wines are more efficient than the present in others beverages that are also rich in antioxidants.

\section{CONCLUSIONS}

The data presented in this work, and their comparison with previous reports, clearly show that the ORAC-PGR/ORAC-FL ratio could be considered as a useful tool to estimate the antioxidant quality of a particular sample. The fact that similar ORAC-PGR/ORAC-FL ratios were obtained for all tested wines implies a similar antioxidant quality of these samples. As consequence, the differences in the antioxidant capacity of red, rose and white wines (estimated by ORAC-PGR or ORAC-FL) can be explained by their different antioxidant concentrations. For this reason, for a better knowledge of the antioxidant parameters of a sample it is important to consider both, the phenol content of the sample (measured by ORAC-FL or Folin indexes) and the average reactivity (measured by the ORAC-PGR/ORAC-FL ratio). Both indexes are relevant in the evaluation of the antioxidant capacity of wines.

\section{ACKNOWLEDGMENTS}

This work was supported by FONDECYT (n¹100659).

\section{REFERENCES}

1 I. Tedesco, M. Russo, P. Russo, G. Iacomino, G.L. Russo, A. Carraturo, C. Faruolo, L. Moio, R. Palumbo, J. Nutr. Biochem. 11,114, (2000).

2 A. M. Cuevas, V. Guasch, O. Castillo, V. Irribarra, C. Mizon, A. San Martin, P. Strobel, D. Perez, A.M. Germain, F. Leighton, Lipids, 35,143, (2000).

3 J. Burns, P.T. Gardner, J. O'Neil, S. Crawford, I. Morecroft, D.B. McPhail, C. Lister, D. Matthews, M.R. MacLean, M.E. Lean, G.G. Duthie, A. Crozier, J. Agric. Food Chem, 48,220, (2000).

4 K. Hotzer, C. Henriquez, E. Pino, S. Miranda-Rottmann, A. Aspillaga, F. Leighton, E. Lissi, Free Radic Res 39,175, (2005).

5 E. Niki, Free Radic. Biol. Med, 49,503, (2010).

6 M.S. Fernandez-Pachón, D. Villano, A.M. Troncoso, M.C. García-Parrilla, Crit. Rev. Food Sci. Nutr, 48,649, (2008).

7 D. Perez, F. Leighton, A. Aspée, C. Aliaga, E. Lissi, Biol. Res, 33,71, (2000)

8 V. Roginsky, E. Lissi, Food Chem, 92,235, (2005).

9 R.L. Prior, G. Cao, Free Radic. Biol. Med, 27,1173, (1999).

10 L.M. Magalhaes, M.A. Segundo, S. Reis, J.L.F.C. Lima. Anal. Chim. Acta, 613,1, (2008)

11 G. Cao, H.M. Alessio, R.G. Cutler, Free Radic. Biol. Med, 14,303, (1993).

12 B. Ou, M. Hampsch-Woodill, R.L. Prior, J. Agric. Food Chem, 49,4619, (2001).

13 A. Dávalos, C. Gómez-Cordovés, B. Bartolomé, J. Agric. Food Chem, $52,48,(2004)$.

14 E. Niki, Methods Enzymol, 186,100, (1990).

15 C. López-Alarcón, E. Lissi, Free Radic. Res, 40,979, (2006).

16 R.H. Bisby, R. Brooke, S. Navartman, Food Chem, 108,1002, (2008).

17 E. Alarcón, A.M. Campos, A.M. Edwards, E. Lissi, C. López-Alarcón, Food Chem, 107,1114, (2008).

18 C. López-Alarcón, E. Lissi, Free Radic. Res, 39,729, (2005).

19 E. Atala, L. Vásquez, H. Speisky, E. Lissi, C. López-Alarcón, Food Chem, 113,331, (2009). 
20 A. Poblete, C. López-Alarcón, E. Lissi, A.M. Campos, J. Chil. Chem. Soc, $54,154,(2009)$

21 Y. Omata, Y. Saito, Y. Yoshida, E. Niki, J. Agric. Food Chem, 56,3386, (2008).

22 Y. Ogawa, Y. Omata, K. Nishio, Y. Saito, Y. Yoshida, E. Niki, Biofactors, 31,237, (2007)

23 Y. Omata, Y. Yoshida, E. Niki, Biosci. Biotechnol. Biochem, 74,531, (2010).
24 V. Singleton, J. Rossi, Am. J. Enol. Vitic, 16,144, (1965).

25 N. Landrault, P. Poucheret, P. Ravel, F. Gasc, G. Cros, P.L. Teissedre, J Agric. Food Chem, 49,3341, (2001)

26 P. Campodonico, E. Barberi, M. Pizarro, C.P. Sotomayor, E. Lissi, J. Chil. Chem. Soc, 43,281, (1998).

27 V. Rastija, G. Srecnik, M. Medic-Saric, Food Chem, 115, 54, (2009).

28 A. M. Campos, E. Lissi, Nutr. Res, 385,385, (1996). 